Review Article

\title{
Effectiveness of Different Topical Treatments in the Healing of Pressure Injuries: A Network Meta-analysis
}

\author{
Luis Furuya-Kanamori MEpi, PhD ${ }^{\mathrm{a}}$, Rachel M. Walker PhD, RN ${ }^{\mathrm{b}, \mathrm{c}, *}$, \\ Brigid M. Gillespie PhD, RN, FACORN ${ }^{\mathrm{b}, \mathrm{d}}$, Justin Clark BA ${ }^{\mathrm{e}}$, \\ Suhail A.R. Doi PhD, FRCP(Edin) ${ }^{a}$, Lukman Thalib MSc, PhD ${ }^{\mathrm{f}}$

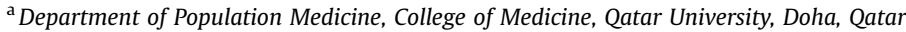 \\ ${ }^{\mathrm{b}}$ School of Nursing and Midwifery, Griffith University, Gold Coast, Australia \\ ${ }^{\mathrm{c}}$ Division of Surgery, Princess Alexandra Hospital, Metro South Health, Brisbane, Australia \\ ${ }^{\mathrm{d}}$ Gold Coast University Hospital, Gold Coast Health, Gold Coast, Australia \\ ${ }^{\mathrm{e}}$ Centre for Research in Evidence Based Practice, Bond University, Gold Coast, Australia \\ ${ }^{\mathrm{f}}$ Department of Public Health, College of Health Sciences, Qatar University, Doha, Qatar
}

\section{Keywords:}

Comparison

meta-analysis

network

pressure injuries

treatment

\begin{abstract}
A B S T R A C T
Objectives: Pressure injuries (PIs) are one of the most common types of complex wounds and impose a huge economic burden on the healthcare system and the patients. A plethora of topical treatments is widely available for PI treatment, yet there is a paucity of evidence with regard to the most effective treatment. The objective of this study was to compare the effect of various topical treatments and identify the best treatment choice(s) for PI healing.

Design: Systematic review and network meta-analysis.

Setting and participants: All published randomized controlled trials that compared the effectiveness of 2 or more of the following dressing groups: basic, foam, active, hydroactive, and other wound dressings. Measures: The outcome was the relative risk (RR) of complete healing following treatment and the generalized pairwise modeling framework was used to generate mixed treatment effects against hydroactive wound dressing, currently the standard of treatment for PIs. All treatments were then ranked by their point estimates.

Results: 40 studies (1757 participants) comparing 5 dressing groups were included in the analysis. All dressings groups ranked better than basic (ie, saline gauze or similar inert dressing). The foam [RR 1.18; 95\% confidence interval (CI) 0.95-1.48] and active wound dressing (RR 1.16; 95\% CI 0.92-1.47) ranked better than hydroactive wound dressing in terms of healing of PIs when the latter was used as the reference group.

Conclusions/Implications: There was substantial uncertainty around the point estimates; however, evidence from our analysis supports the use of hydroactive wound dressings to replace basic dressings. Foam and active wound dressing groups seem promising and therefore need further investigation. Highquality, rigorously conducted research about the clinical effectiveness of the topical treatments in these 2 groups developed in consultation with health professionals, patients, and their carers is needed to identify if indeed foam and active wound dressings provide advantages over hydroactive dressings.
\end{abstract}

(C) 2018 AMDA - The Society for Post-Acute and Long-Term Care Medicine.

\footnotetext{
L. Furuya-Kanamori and R. M. Walker are joint first authors.

S. A. R. Doi and L. Thalib are joint senior authors.

This research was supported by Qatar University Internal Grant No. QUUG-CHSCHS-15 $\backslash 16-1$. The findings detailed herein are solely the responsibility of the authors with no interference by the funder.

The authors declare no conflicts of interest.

* Address correspondence to Rachel M. Walker, PhD, RN, Nursing Practice Development Unit, Building 15, Level 2, Princess Alexandra Hospital (PAH), Ipswich Road, Woolloongabba QLD 4102, Australia.

E-mail address: r.walker@griffith.edu.au (R.M. Walker).
}

Pressure injuries (PIs), ${ }^{1}$ also known as pressure ulcers or bed-sores, are wounds involving the skin and sometimes the tissue on bony parts of the body, often occurring over bony prominences such as the sacrum and heel. ${ }^{2}$ They are caused by a combination of pressure, shear, and friction that leads to microcirculatory occlusion, resulting in stimulation of inflammatory processes. ${ }^{2}$ This in turn can lead to cell death, ulceration, and tissue necrosis. ${ }^{3}$ PIs can have a significant impact on those affected, as they can cause pain and infection that can increase patient's hospital length of stay and significantly decrease 
their health-related quality of life. ${ }^{4}$ People at high risk of developing PIs include those with limited mobility such as older people, people with short- or long-term medical conditions, and those with spinal injuries. ${ }^{5}$ Lack of mobility, reduced sensory perception, poor nutrition, and hydration as well as lack of blood flow can all increase the risk of developing PIs. ${ }^{5}$ Development of PI can be rapid and lead to irreversible tissue damage in vulnerable patients after as little as $30 \mathrm{mi}-$ nutes of uninterrupted pressure. ${ }^{6}$

Globally, PIs are one of the most common types of complex wounds. An estimated 2.5 million people are affected annually in the US alone. ${ }^{7}$ A large European pilot study estimated the hospital PI point prevalence to be $10.5 \%{ }^{8}$ National PI data collected in the UK's National Health Service (NHS) reported a prevalence of $4.2 \%$ across community and acute care settings in September $2017,{ }^{9}$ although the study could have underestimated the actual prevalence of PIs in the United Kingdom because of the low sensitivity of the tool used to identify the cases. ${ }^{10,11}$ Prevalence of PIs can vary according to setting and can be as high as $26 \%$ in some settings such as long-term, acute-care, and rehabilitation settings. ${ }^{12}$

Managing PIs can be expensive. Annual health care costs associated with PIs in the United Kingdom in 2012-2013 were estimated to be in the range GBP 4.5 to 5.1 billion. ${ }^{13}$ In the USA in 2014 alone, treatment for PIs were estimated at USD 9.1 to 11.6 billion annually with 2.5 million people affected and approximately 60,000 deaths resulting from PIs. ${ }^{14}$ The total costs to the Australian health care system for treating PIs have been estimated at AUD 1.8 billion annually or $9 \%$ of public hospital expenditure. ${ }^{15}$ Although dated, these cost estimates provide an insight about the substantial financial burden PIs represent within contemporary health contexts.

In terms of the treatment of PIs, there are 2 major strategies that are currently being employed: (1) the use of pressurerelieving support surfaces (eg, alternating pressure air mattresses) and (2) management of ulcers using topical treatments such as wound dressings. ${ }^{16,17}$ Other general strategies for treating and healing PIs include optimizing circulation/perfusion, improving nutrition and the treatment of clinical infection. ${ }^{2,16}$ Topical treatments are widely used to treat PIs, there are a plethora of options to choose from including alginate, hydrocolloid, proteasemodulating dressings, topical agents, and other therapies. Despite this, there is paucity of evidence to facilitate decision making regarding the type of topical treatments that are the most clinically effective. This is despite many published meta-analyses examining effects of dressings, negative-pressure wound therapy, and topical agents on healing of PIs in mainly adult populations in care settings. ${ }^{18-22}$

A key issue has been the statistical methods used in previous reviews of topical treatments such as hydrogel, ${ }^{19}$ alginate, ${ }^{18}$ and foam $^{22}$ as well as other therapies such as negative-pressure wound therapy ${ }^{20}$ which only allowed pairwise comparisons. Results from these reviews consistently reported low to very low certainty of evidence from included studies because of high risk of bias (lack of allocation concealment and blind assessment) and imprecision (small studies and incomplete reporting). More significantly, they were unable to provide clear advice on effectiveness of the topical treatment in healing PIs. While we were undertaking this project, an attempt to address this limitation via a network meta-analysis was published. ${ }^{21}$ However, the authors of the study were still unable to determine which topical treatments were the most likely to heal PIs because sparseness of their network led to inconclusive results. $^{23}$ Our approach differs from the latter in several ways, including in the classification of topical treatments, extent of coverage of studies, and methodology used, which brings much more clarity to this issue and does away with the issue of sparseness.

\section{Methods}

Findings of this systematic review and meta-analysis are presented according to PRISMA reporting guidelines. ${ }^{24}$

\section{Search Strategy}

The original search strategy was designed in PubMed and converted for use in the following databases using the Systematic Reviews Accelerators Polyglot Search Translation module, ${ }^{25}$ with no limitations on year or language: CINAHL, Embase, Web of Science, Scopus, and the Cochrane Central Register of Controlled Trials (CENTRAL). The initial search was conducted on September 15, 2016, and updated on December 1, 2017. Search terms related to pressure injuries, pressure ulcers, topical treatment types, and outcome measurements (ie, healing) were included. The full search strategy is shown in Supplementary Material S1. In order to achieve a comprehensive evaluation of the published evidence, the systematic search was supplemented with a forward and backward citation search as well as retrieving the first 20 similar articles from PubMed for each of the papers included from the searches. We sought additional papers from the reference lists of relevant meta-analyses and review papers. ${ }^{16,19-21,26,27}$

Titles and abstracts of all papers that were extracted by the search engine were uploaded to the Rayyan platform (http://rayyan.qcri. $\operatorname{org} /$ ) which is a web application developed by Qatar Computing Research Institute (Data Analytics). ${ }^{28}$ Five authors (LFK, RW, BG, SD, and LT) independently screened the titles and abstracts on the Rayyan platform. Any disagreements were resolved through author consensus. Additionally, LFK and RW examined the full-text papers for eligibility against the review protocol. Disagreements were resolved through consensus and by involvement of a third author (BG).

\section{Selection Criteria}

Eligible studies were published and unpublished randomized controlled trials (RCTs) that enrolled patients with stage 2 to 4 PIs and compared the effectiveness of 2 or more of the following 13 narrow topical treatment categories: antimicrobial, basic (ie, gauze with normal saline), collagenase, collagen, combined treatment (ie, when multiple active components were included), film, foam (ie, Lyofoam, polyurethane), growth factors, hydrocolloid, hydrogel, moisture retentive (ie, calcium alginate), negative pressure, and radiant heat. These dressings were selected because they were either (1) identified in the literature as wound care products used for the treatment of PIs; (2) available to clinicians for use in routine practice; (3) recommended by international clinical guidelines ${ }^{2}$; or (4) under investigation as an experimental or alternative dressing for the treatment of PIs. Dressings were grouped according to their dominant element. The network using these 13 narrowly defined topical treatment categories initially selected was noted to be sparse. The key issue with this is that networks that are not well connected may provide unreliable estimates and rank treatment options incorrectly and/or may lead to inconsistent ranking of the dressing when the reference category changes.

For these reasons, a parallel analysis using a broader classification based on mechanisms of action provided by $\operatorname{Horn}^{29}$ was conducted. This classification defined 5 dressing groups as follows: basic wound dressing (ie, inert materials like saline gauze), hydroactive wound dressing (ie, hydrocolloid, hydrogel, moisture-retentive dressings), foam dressing, active wound dressing (ie, collagen, growth factors), and other wound dressing (ie, antimicrobial, collagenase, film, negative pressure, radiant heat) to achieve a network that was not sparse. These 2 classifications are given in Table 1. 
Table 1

Classification of the Dressings

\begin{tabular}{|c|c|c|c|}
\hline \multicolumn{2}{|c|}{ Topical Treatment Categories } & \multirow{2}{*}{$\begin{array}{l}\text { Wound Dressing } \\
\text { Groups } \\
\text { BWD }\end{array}$} & \multirow{2}{*}{$\begin{array}{l}\text { Description } \\
\text { Inactive dressings can pick up secretions from the wound, but do } \\
\text { not create a specific microenvironment that promotes wound } \\
\text { healing. }\end{array}$} \\
\hline BAS & Basic (eg, saline gauze, placebo) & & \\
\hline $\mathrm{HCD}$ & Hydrocolloid (eg, DuoDerm, Comfeel Plus, Tegaderm) & \multirow[t]{3}{*}{ HWD } & \multirow{3}{*}{$\begin{array}{l}\text { Hydroactive wound dressings accelerate wound healing by altering } \\
\text { the microclimate of the wound and imitating the physiological } \\
\text { process to form a moist wound environment. }\end{array}$} \\
\hline HGD & $\begin{array}{l}\text { Hydrogel (eg, Askina Transorbent, BioFilm hydrogel, Acemannan } \\
\text { hydrogel) }\end{array}$ & & \\
\hline MRD & Moisture retentive (eg, UrgoSorb, Aquacel) & & \\
\hline FOA & Foam (eg, Epi-Lock dressing, Allevyn hydrocellular foam, Spyrosorb) & FOA & $\begin{array}{l}\text { Foam dressings absorb wound exudate, insulate the wound and } \\
\text { provide a moist wound healing environment. }\end{array}$ \\
\hline $\mathrm{COL}$ & Collagen (eg, Promogran, Medifil Collagen Particles) & AWD & Active dressings have a defined mechanism of action through which \\
\hline GRF & $\begin{array}{l}\text { Growth factor (eg, Dermagraft, Transforming growth factor beta-3, } \\
\text { Recombinant platelet-derived growth factor-BB) }\end{array}$ & & $\begin{array}{l}\text { they intervene in the pathophysiological processes in the wound } \\
\text { by substitution and suppression or alteration of factors. }\end{array}$ \\
\hline AMD & $\begin{array}{l}\text { Antimicrobial (eg, Cadexomer iodine, povidine soaked wet gauze, } \\
\text { Dakin solution) }\end{array}$ & OWD & Wound dressings with other mechanisms of action \\
\hline CLD & Collagenase (eg, Iruxol mono ointment) & & \\
\hline FIL & Film (eg, 3M Tegaderm Absorbent Clear Acrylic Dressing) & & \\
\hline NPD & Negative pressure (eg, V.A.C. therapy system) & & \\
\hline RHD & Radiant heat (eg, Augustine Medical warm-up) & & \\
\hline COM & Combined-multiple active compoenents & \multicolumn{2}{|c|}{$\begin{array}{l}\text { Classified in a dressing group depending on the type of combination of the active } \\
\text { ingredients. }\end{array}$} \\
\hline
\end{tabular}

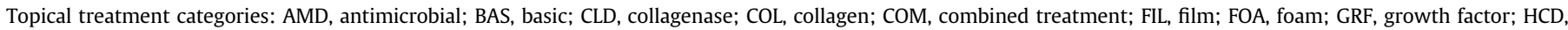

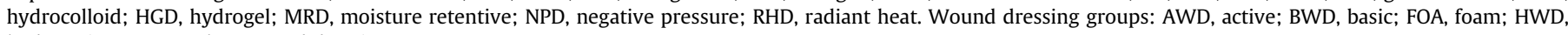
hydroactive; OWD, other wound dressing.

Studies were also excluded if they assessed effectiveness more than 1 year post-treatment or included other types of wounds (eg, chronic wound and venous leg ulcers). Because we used a pairwise modeling approach (described below), if studies compared an odd number of eligible treatments, we selected a pair (or multiple pairs) of treatments for inclusion in meta-analysis. In such cases, we prioritized the inclusion of treatments with the lowest dose and that are currently in widespread use for PI healing over novel treatments.

\section{Data Extraction}

Data extraction was performed by L.F.K. and R.W. We extracted the year and country of study; study population topical treatment names, types, and schedules; sample size; number of people "healed" and "not healed" after treatment; and follow-up time. If a study compared the same intervention in both arms, it was assumed that the effect of such an intervention canceled itself from both arms (eg, a RCT compared hydrocolloid + hydrogel against hydrocolloid + collagen, it was considered as hydrogel compared to collagen), and dressings were classified according to the remaining active ingredients.

\section{Quality Assessment}

Quality of included studies was assessed using the Cochrane Collaboration's tool for assessing risk of bias in randomized trials. ${ }^{30}$ This scale assessed studies for risk of bias using items related to random sequence generation, allocation concealment, selective reporting, blinding, incomplete data, and attrition rate (Supplementary Material S2).

\section{Statistical Analysis}

We aimed to examine healing rate; that is the proportion of treated individuals whose PIs healed completely based on the cure criteria, where reported in each study. The outcome calculated for each study was the relative risk (RR) of cure following topical treatment. We used an automated generalized pairwise modeling (GPM) framework ${ }^{31}$ to generate mixed treatment effects against basic dressings, currently the simplest standard treatment. This framework requires no additional assumptions other than that of transitivity, and uses an automated process to extend the previously reported Bucher method ${ }^{32}$ for single 3-treatment loops. The method involves: (1) pooling effect sizes for direct comparisons between each combination of 2 treatments using meta-analysis; (2) performing indirect comparisons by automated generation of all possible closed loops of 3 treatments such that one is common to 2 studies; and (3) pooling all direct and indirect effects using meta-analysis to give a final effect size comparing each treatment to the common comparator. To pool estimates, we used the inverse variance heterogeneity model, which uses a quasi-likelihood based variance structure without distributional assumptions and has been shown to perform better when compared to the random effects method. ${ }^{33}$ For comparison, all analyses were re-run using the random effects model within a multivariate frequentist framework. ${ }^{34}$

We assessed statistical heterogeneity across pooled direct effects using Cochran's $Q$ and the $H$ index. The $H$ index is the square root of $H^{2}$, the estimated residual variance from the regression of the standardized treatment effect estimates against the inverse standard error in each direct meta-analysis. $H$ was computed as follows:

$H=\sqrt{\frac{\max [\max (1, n-1), Q]}{\max (1, n-1)}}$

where $n$ is the number of study estimates and $Q$ represents the chi quared from Cochran's $Q$.

Transitivity across the network was assessed by examining inconsistency across the network using the weighted pooled $H$ index $(\bar{H})$, which was computed from Cochran's $Q$ as follows:

$\bar{H}=\sqrt{\frac{\sum_{j=1}^{k} \max [\max (1, n-1), Q]}{\left(\sum_{j=1}^{k} n\right)-k+s}}$

where $n$ is the number of estimates pooled across each comparison and $s$ is the number comparisons (out of $k$ ) where $n=1$. The minimum value $H$ or $\bar{H}$ can take is $1 . \bar{H}<3$ was taken to be minimal inconsistency based on our simulations in homogenous direct meta-analyses. 


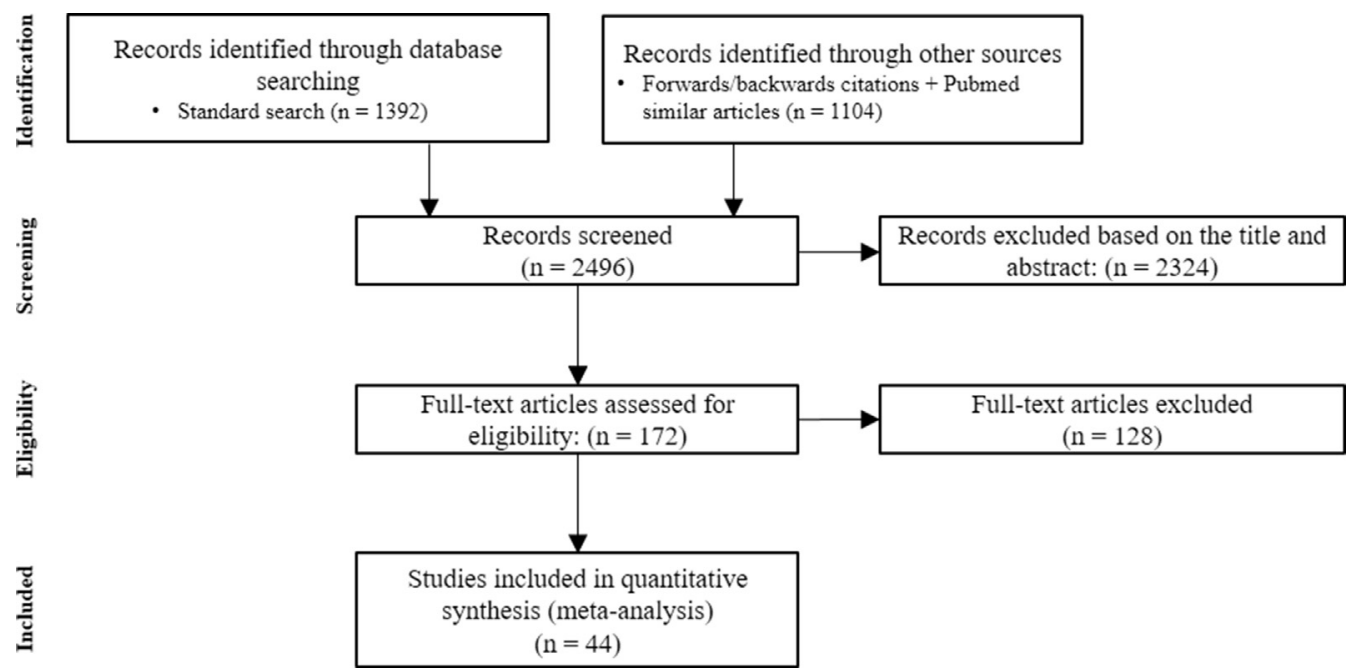

Fig. 1. PRISMA flow diagram of study selection for quantitative synthesis.

Sensitivity analyses were performed based on restricting the network to studies that examined efficacy within 6 to 12 weeks and to assess the impact of the risk of bias on the results (using a quality effects model ${ }^{35}$ ).

Publication bias was assessed using "comparison-adjusted" funnel plots, that plots the difference of each study's observed $\ln (\mathrm{RR})$ versus the comparison's mean $\ln (\mathrm{RR})$ obtained from meta-analysis on the horizontal axis. In the absence of small-study effects, studies are expected to form an inverted funnel centered at zero. ${ }^{36}$

All analyses involved in the generalized pairwise modeling (GPM) framework were conducted using MetaXL version 5.3 (EpiGear; Brisbane, Australia) developed by one of us (S.D.). Funnel and network plots were created in Stata, version 14.1 (College Station, TX).

\section{Role of Funding Sources}

This research was supported by Qatar University Internal Grant No. QUUG-CHS-CHS-15 \16-1. The findings detailed herein are solely the responsibility of the authors with no interference by the funder.

\section{Results}

\section{Identified Studies}

Database searches, forward and backward citation search, and retrieving the first 20 similar articles from PubMed identified 2496 studies that were initially screened by title and abstract, from which 172 potentially relevant papers were selected. Of these, 44 met the inclusion criteria for the systematic review and were included in the network meta-analysis (Figure 1).

\section{Characteristics of Included Studies}

The 44 included studies were published between 1983 and 2015. Studies were conducted in Asia (2 countries [Korea and Iran], 2 studies), North America (1 country [USA]; 21 studies), and Europe (10 countries [Denmark, Finland, France, Germany, Italy, Netherlands, Poland, Spain, Sweden, and UK]; 21 studies).

Twenty studies had a comparison to basic dressing, and 31 studies to a hydroactive dressing; representing the 2 most common topical treatments. The remaining studies had a variety of topical treatment types. Complete healing was assessed at a median follow-up of 8 weeks (IQR 6.5-13 weeks) with a range of $1.5-52$ weeks (Table 2).

\section{Included Topical Treatments}

A total of 13 topical treatment categories and 5 dressing wound groups were included in the network meta-analyses. Topical treatments within the same category were deemed exchangeable (Table 2). Figure 2 depicts the network plot showing the comparison groups for each study.

\section{Quantitative Synthesis}

Based on 44 studies examining treatment of PIs, when basic dressing was used as the reference treatment category, all topical treatment categories were found to have a better rank than basic dressing being negative pressure, film, and combined treatment the ones with the biggest effect size. Combined treatment (RR 1.88; 95\% CI $1.08-3.25$ ) was found to be the only dressing category to have statistically significant improvement in healing when compared to basic dressings (Figure 3A). When hydrocolloid was used as the reference category in the analysis, the ranking of the dressing categories dramatically changed (Figure $3 \mathrm{~B}$ ). It is clear from the results that the network with 13 dressing categories was sparse, the point estimates were not reliable, and the ranking of the treatments was not stable. This analysis was not informative, and therefore we proceeded with the next analysis.

When the analysis was carried out using the 5 wound dressing groups as defined by Horn, ${ }^{29} 40$ studies were included; 4 studies $^{44,45,49,60}$ were excluded because they compared wound dressings within the same group. The basic wound dressings was used as the reference group, all dressings groups were better in rank than basic dressings. In ascending order of efficacy based on the point estimate, the ranking was other, hydroactive, active, and foam dressings and only the latter being statistically significantly better (Figure 4A). The ranking of dressing groups remained unchanged when the hydroactive dressings was used as the reference (Figure $4 \mathrm{~B}$ and Supplementary Material S3), revealing a stable (nonsparse) network with reliable results.

Analysis using a conventional approach (ie, multivariate frequentist framework) did not alter the ranking nor the pooled 
Table 2

Characteristics of the Included Studies

\begin{tabular}{|c|c|c|c|c|c|c|c|}
\hline $\begin{array}{l}\text { First Author } \\
\text { and Year of } \\
\text { Publication }\end{array}$ & $\begin{array}{l}\text { Study } \\
\text { Location }\end{array}$ & $\begin{array}{l}\text { Follow-up } \\
\text { Duration }\end{array}$ & $\begin{array}{l}\text { Topical } \\
\text { Treatments }\end{array}$ & $\begin{array}{l}\text { Topical } \\
\text { Treatment } \\
\text { Category }\end{array}$ & $\begin{array}{l}\text { Wound } \\
\text { Dressing } \\
\text { Group }\end{array}$ & $\begin{array}{l}\text { Number of } \\
\text { Participants } \\
\text { (Healed/ } \\
\text { Treated) }\end{array}$ & $\begin{array}{l}\text { Criteria for } \\
\text { Complete Healing }\end{array}$ \\
\hline \multirow{2}{*}{$\operatorname{Alm}(1989)^{37}$} & \multirow[t]{2}{*}{ Sweden } & \multirow[t]{2}{*}{$6 \mathrm{wk}$} & Hydrocolloid & $\mathrm{HCD}$ & HWD & $17 / 31$ & \multirow[t]{2}{*}{ Area of the PI equal to zero } \\
\hline & & & Saline gauze & BAS & BWD & $4 / 25$ & \\
\hline \multirow{2}{*}{$\begin{array}{l}\text { Anguilo-Sanchez } \\
(2001)^{38}\end{array}$} & \multirow[t]{2}{*}{ Spain } & \multirow[t]{2}{*}{$7 \mathrm{wk}$} & Alginate and hydrocolloid & $\mathrm{COM}$ & HWD & $20 / 35$ & \multirow[t]{2}{*}{ Not reported } \\
\hline & & & Saline gauze & BAS & BWD & $10 / 35$ & \\
\hline \multirow[t]{2}{*}{ Ashby $(2012)^{39}$} & \multirow[t]{2}{*}{ UK } & \multirow[t]{2}{*}{$26 \mathrm{wk}$} & Hydrocolloid, alginate & $\mathrm{COM}$ & HWD & $0 / 6$ & \multirow{2}{*}{$\begin{array}{l}\text { Epithelialization and cessation of } \\
\text { treatment to achieve healing }\end{array}$} \\
\hline & & & Negative-pressure dressing & NPD & OWD & $1 / 6$ & \\
\hline \multirow[t]{2}{*}{ Bale $(1997)^{40}$} & \multirow[t]{2}{*}{ UK } & $4 \mathrm{wk}$ & Polyurethane foams & FOA & FOA & $7 / 29$ & Not reported \\
\hline & & & Hydrocolloid & $\mathrm{HCD}$ & HWD & $5 / 31$ & \\
\hline Banks (1994a) $)^{41}$ & UK & $6 \mathrm{wk}$ & $\begin{array}{l}\text { Semipermeable polyurethane } \\
\text { dressing }\end{array}$ & FOA & FOA & $11 / 13$ & Not reported \\
\hline & & & Hydrocolloid & $\mathrm{HCD}$ & HWD & $10 / 16$ & \\
\hline Banks $(1994 b)^{42}$ & UK & $12 \mathrm{wk}$ & Polyurethane dressing & FOA & FOA & $12 / 20$ & Not reported \\
\hline & & & Hydrocolloid & $\mathrm{HCD}$ & HWD & $10 / 20$ & \\
\hline Belmin $(2002)^{43, *}$ & France & $8 w k$ & Hydrocolloid & BAS & BWD & $31 / 53$ & Surface area reduction $\geq 40 \%$ \\
\hline & & & Calcium alginate and hydrocolloid & MRD & HWD & $43 / 57$ & \\
\hline $\operatorname{Brod}(1990)^{44, \dagger}$ & USA & $8 \mathrm{wk}$ & $\begin{array}{l}\text { Poly(HEMA) dissolved in } \\
\text { polyethylene glycol }\end{array}$ & HGD & HWD & $14 / 27$ & Not reported \\
\hline & & & Hydrocolloid & HCD & HWD & $10 / 16$ & \\
\hline Brown-Etris $(1996)^{45, \dagger}$ & USA & $10 \mathrm{wk}$ & Hydrogel & HGD & HWD & $39 / 77$ & Not reported \\
\hline & & & Hydrocolloid & $\mathrm{HCD}$ & HWD & $37 / 77$ & \\
\hline Brown-Etris $(2008)^{46}$ & USA & $8 \mathrm{wk}$ & Hydrocolloid & $\mathrm{HCD}$ & HWD & $22 / 37$ & Closed PI wounds \\
\hline & & & Transparent absorbent acrylic & FIL & OWD & $21 / 35$ & \\
\hline Burgos $(2000)^{47}$ & Spain & $12 \mathrm{wk}$ & Hydrocolloid & HCD & HWD & $3 / 19$ & PI with final surface area of zero \\
\hline & & & Collagenase ointment & CLD & OWD & $3 / 18$ & \\
\hline Colwell $(1993)^{48}$ & USA & $12 \mathrm{wk}$ & Hydrocolloid wafer dressing & HCD & HWD & $11 / 33$ & PI completely covered with \\
\hline & & & Saline gauze & BAS & BWD & $1 / 37$ & epithelial tissue \\
\hline Darkovich $(1990)^{49, \dagger}$ & USA & $8.5 \mathrm{wk}$ & Hydrocolloid & HCD & HWD & $9 / 36$ & PI wound closure \\
\hline & & & Biofilm hydrogel & HGD & HWD & $12 / 35$ & \\
\hline Ford $(2002)^{50}$ & USA & $6 \mathrm{wk}$ & Vacuum-assisted closure & NPD & OWD & $2 / 20$ & Not reported \\
\hline & & & Healthpoint system & $\mathrm{COM}$ & HWD & $2 / 15$ & \\
\hline Gorse $(1987)^{51}$ & USA & $11 \mathrm{wk}$ & Hydrocolloid & HCD & HWD & $54 / 76$ & Not reported \\
\hline & & & $\begin{array}{l}\text { Wet-to-dry dressing with Dakin } \\
\text { solution }\end{array}$ & AMD & OWD & $26 / 52$ & \\
\hline Graumlich $(2003)^{52}$ & USA & $8 w k$ & Hydrocolloid & HCD & HWD & $15 / 30$ & Not reported \\
\hline & & & Collagen & $\mathrm{COL}$ & AWD & $18 / 35$ & \\
\hline Hirshberg $(2001)^{53, \ddagger}$ & USA & $16 \mathrm{wk}$ & TGF- $\beta 31 \mu \mathrm{g} / \mathrm{cm}^{2}$ & GRF & AWD & $0 / 4$ & Not reported \\
\hline & & & TGF- $\beta 32.5 \mu \mathrm{g} / \mathrm{cm}^{2}$ (excluded arm) & - & - & - & \\
\hline & & & Placebo gel & BAS & BWD & $0 / 5$ & \\
\hline Hollisaz $(2004)^{54, \S}$ & Iran & $8 w k$ & Hydrocolloid & HCD & HWD & $12 / 18$ & Intact dermis and epidermis, no \\
\hline & & & Saline gauze & BAS & BWD & $3 / 19$ & abrasion or ulceration \\
\hline & & & Phenytoin cream (excluded arm) & - & - & - & \\
\hline $\operatorname{Kim}(1996)^{55}$ & Korea & $7.6 \mathrm{wk}$ & Hydrocolloid & $\mathrm{HCD}$ & HWD & $21 / 26$ & When no further dressing was \\
\hline & & & $\begin{array}{l}\text { Wet-to-dry dressing with povidone } \\
\text { iodine }\end{array}$ & AMD & OWD & $14 / 18$ & required \\
\hline Kraft $(1993)^{56}$ & USA & $24 \mathrm{wk}$ & Saline gauze & BAS & BWS & $3 / 14$ & Not reported \\
\hline & & & Epi-Lock dressing & FOA & HWS & $10 / 24$ & \\
\hline Kuflik $(2001)^{57, \|}$ & USA & $6 \mathrm{wk}$ & ResurfixR & COM & AWD & $2 / 5$ & Not reported \\
\hline & & & Petrolatum jelly & BAS & BWD & $0 / 3$ & \\
\hline Landi $(2003)^{58}$ & Italy & $6 \mathrm{wk}$ & Topical nerve growth factor & GRF & AWD & $8 / 18$ & Not reported \\
\hline & & & Balanced salt solution & BAS & BWD & $1 / 18$ & \\
\hline Matzen $(1999)^{59}$ & Denmark & $12 \mathrm{wk}$ & Saline gauze & BAS & BWD & $0 / 15$ & Not reported \\
\hline & & & Hydrocolloid & HCD & HWD & $5 / 17$ & \\
\hline Moberg $(1983)^{60, \dagger}$ & Sweden & $8 w k$ & $\begin{array}{l}\text { Saline, enzyme debriding, or } \\
\text { nonadhesive dressing }\end{array}$ & $\mathrm{COM}$ & OWD & $1 / 18$ & Not reported \\
\hline & & & Cadexomer iodine & AMD & OWD & $6 / 16$ & \\
\hline Muller $(2001)^{61}$ & Netherlands & $14 \mathrm{wk}$ & Collagenase ointment & CLD & OWD & $11 / 12$ & Total epithelialization of PIs \\
\hline & & & Hydrocolloid & $\mathrm{HCD}$ & HWD & $7 / 11$ & \\
\hline Mustoe $(1994)^{62, \text { }}$ & USA & $26 \mathrm{wk}$ & rPDGF-BB $100 \mu \mathrm{g} / \mathrm{mL}$ & GRF & AWD & $2 / 15$ & Area of opening being equal to zero \\
\hline & & & $\begin{array}{l}\text { rPDGF-BB } 300 \mu \mathrm{g} / \mathrm{mL} \text { (excluded } \\
\text { arm) }\end{array}$ & - & - & - & \\
\hline & & & Placebo-Growth factor excluded & BAS & BWD & $1 / 14$ & \\
\hline Neill $(1989)^{63}$ & USA & $8 w k$ & Hydrocolloid & HCD & HWD & $13 / 42$ & Not reported \\
\hline & & & Saline gauze & BAS & BWD & $10 / 45$ & \\
\hline Nisi $(2005)^{64}$ & Italy & $26 \mathrm{wk}$ & Povidone iodine plus paraffin & AMD & OWD & $28 / 40$ & Not reported \\
\hline & & & Protease modulating matrix & $\mathrm{COL}$ & AWD & $36 / 40$ & \\
\hline Oleske $(1986)^{65}$ & USA & $1.5 \mathrm{wk}$ & $\begin{array}{l}\text { Polyurethane self-adhesive foam } \\
\text { dressing }\end{array}$ & FOA & HWD & $0 / 5$ & Not reported \\
\hline & & & Saline gauze & BAS & BWD & $0 / 5$ & \\
\hline
\end{tabular}


Table 2 (continued)

\begin{tabular}{|c|c|c|c|c|c|c|c|}
\hline $\begin{array}{l}\text { First Author } \\
\text { and Year of } \\
\text { Publication }\end{array}$ & $\begin{array}{l}\text { Study } \\
\text { Location }\end{array}$ & $\begin{array}{l}\text { Follow-up } \\
\text { Duration }\end{array}$ & $\begin{array}{l}\text { Topical } \\
\text { Treatments }\end{array}$ & $\begin{array}{l}\text { Topical } \\
\text { Treatment } \\
\text { Category }\end{array}$ & $\begin{array}{l}\text { Wound } \\
\text { Dressing } \\
\text { Group }\end{array}$ & $\begin{array}{l}\text { Number of } \\
\text { Participants } \\
\text { (Healed/ } \\
\text { Treated) }\end{array}$ & $\begin{array}{l}\text { Criteria for } \\
\text { Complete Healing }\end{array}$ \\
\hline \multirow[t]{4}{*}{ Payne $(2001)^{66, * *}$} & \multirow[t]{4}{*}{ USA } & \multirow[t]{4}{*}{$52 \mathrm{wk}$} & GM-CSF & GRF & AWD & $12 / 15$ & \multirow[t]{4}{*}{ Wound closure $\geq 85 \%$} \\
\hline & & & Placebo & BAS & BWD & $10 / 15$ & \\
\hline & & & bFGF (excluded arm) & - & - & - & \\
\hline & & & $\begin{array}{l}\text { Sequential GM-CSF and bFGF } \\
\text { (excluded arm) }\end{array}$ & - & - & - & \\
\hline \multirow[t]{2}{*}{ Payne $(2004)^{67}$} & \multirow[t]{2}{*}{ USA } & \multirow[t]{2}{*}{$24 \mathrm{wk}$} & Saline gauze & BAS & HWD & $2 / 16$ & \multirow{2}{*}{$\begin{array}{l}\text { Full epithelialization and the } \\
\text { absence of drainage }\end{array}$} \\
\hline & & & Dermagraft & GRF & AWD & $2 / 18$ & \\
\hline \multirow[t]{2}{*}{ Payne $(2009)^{68}$} & \multirow[t]{2}{*}{ USA } & \multirow[t]{2}{*}{$4 \mathrm{wk}$} & $\begin{array}{l}\text { Self-adhesive polyurethane foam } \\
\text { dressing }\end{array}$ & FOA & HWD & $10 / 20$ & \multirow[t]{2}{*}{ Not reported } \\
\hline & & & Saline gauze & BAS & BWD & $6 / 16$ & \\
\hline \multirow[t]{2}{*}{ Piatkowski $(2012)^{69, \dagger \dagger}$} & \multirow[t]{2}{*}{ Germany } & \multirow[t]{2}{*}{$3 \mathrm{wk}$} & $\begin{array}{l}\text { Polyurethane foam } \\
\text { dressing + collagen }\end{array}$ & $\mathrm{COL}$ & AWD & $5 / 5$ & \multirow[t]{2}{*}{ Not reported } \\
\hline & & & Polyurethane foam dressing & BAS & BWD & $4 / 5$ & \\
\hline \multirow[t]{2}{*}{ Price $(2000)^{70}$} & \multirow[t]{2}{*}{ UK } & \multirow[t]{2}{*}{$6 \mathrm{wk}$} & Alginates & MRD & HWD & $2 / 25$ & \multirow[t]{2}{*}{ Not reported } \\
\hline & & & Radiant heat dressing & RHD & OWD & $3 / 25$ & \\
\hline \multirow{4}{*}{$\begin{array}{l}\text { Ramos-Torrecillas } \\
\quad(2015)^{71, \pm}\end{array}$} & \multirow[t]{4}{*}{ Spain } & \multirow[t]{4}{*}{$5 \mathrm{wk}$} & Saline gauze & BAS & HWD & $0 / 25$ & \multirow[t]{4}{*}{ Total closure of the PI } \\
\hline & & & PRGF & GRF & AWD & $3 / 34$ & \\
\hline & & & 2 doses of PRGF (excluded arm) & - & - & - & \\
\hline & & & $\begin{array}{l}\text { PRGF + hyaluronic acid (excluded } \\
\text { arm) }\end{array}$ & - & - & - & \\
\hline \multirow[t]{4}{*}{ Rees $(1999)^{72, \S \S}$} & \multirow[t]{4}{*}{ USA } & \multirow[t]{4}{*}{$16 \mathrm{wk}$} & Saline gauze & BAS & BWD & $0 / 31$ & 100\% healed PIs \\
\hline & & & Becaplermin gel $100 \mu \mathrm{g} / \mathrm{g}$ only & GRF & AWD & $7 / 31$ & \\
\hline & & & $\begin{array}{l}\text { Becaplermin gel } 100 \mu \mathrm{g} / \mathrm{g} \\
\text { alternated with placebo } \\
\text { (excluded arm) }\end{array}$ & - & - & - & \\
\hline & & & $\begin{array}{l}\text { Becaplermin gel } 300 \mu \mathrm{g} / \mathrm{g} \\
\text { alternated with placebo } \\
\text { [excluded arm] }\end{array}$ & - & - & - & \\
\hline Scevola $(2010)^{73}$ & Italy & $14 \mathrm{wk}$ & Allogenic platelet gel & GRF & AWD & $0 / 8$ & Not reported \\
\hline & & & Standard treatment & $\mathrm{COM}$ & HWD & $0 / 8$ & \\
\hline Sebern $(1986)^{74}$ & USA & $8 \mathrm{wk}$ & Moisture vapor permeable dressing & FIL & OWD & $14 / 22$ & Not reported \\
\hline & & & Wet-to-dry gauze & BAS & BWD & $0 / 12$ & \\
\hline Seeley $(1999)^{75}$ & USA & $8 \mathrm{wk}$ & Hydrocolloid & HCD & HWD & $8 / 19$ & Closed PI \\
\hline & & & Hydrocellular foam & FOA & FOA & $8 / 20$ & \\
\hline Sipponen $(2008)^{76}$ & Finland & $26 \mathrm{wk}$ & $\begin{array}{l}\text { Sodium carboxymethylcellulose } \\
\text { hydrocolloid polymer }\end{array}$ & MRD & HWD & $4 / 9$ & Not reported \\
\hline & & & Resin salve of the Norway spruce & AMD & OWD & $12 / 13$ & \\
\hline Sopata $(2002)^{77}$ & Poland & $8 \mathrm{wk}$ & Lyofoam & FOA & FOA & $15 / 18$ & Closed PI wounds \\
\hline & & & Hydrogel & HGD & HWD & $15 / 20$ & \\
\hline Thomas $(1998)^{78}$ & UK & $10 \mathrm{wk}$ & Acemannan hydrogel & HGD & HWD & $10 / 16$ & Not reported \\
\hline & & & Saline gauze & BAS & BWD & $9 / 14$ & \\
\hline Thomas $(2005)^{79}$ & UK & $12 \mathrm{wk}$ & Hydrocolloid & $\mathrm{HCD}$ & HWD & $7 / 20$ & Not reported \\
\hline & & & Radiant heat dressing & RHD & OWD & $8 / 21$ & \\
\hline Xakellis $(1992)^{80}$ & USA & $10 \mathrm{wk}$ & Hydrocolloid & HCD & HWD & $16 / 18$ & PI had epithelial covering \\
\hline & & & Saline gauze & BAS & BWD & $18 / 21$ & \\
\hline
\end{tabular}

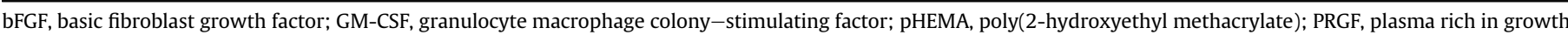
factor; rhPDGF-BB, recombinant human platelet-derived growth factor-BB; TGF- $\beta 3$, transforming growth factor, beta 3.

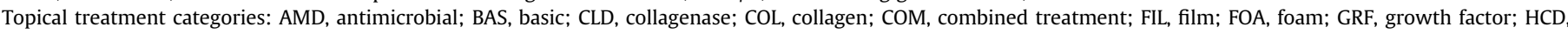

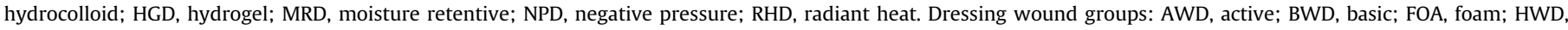
hydroactive; OWD, other wound dressing.

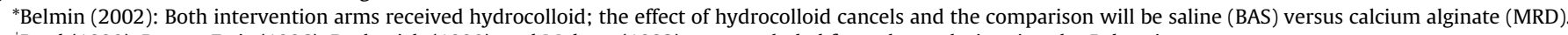

'Brod (1990), Brown-Etris (1996), Darkovich (1990), and Moberg (1983) were excluded from the analysis using the 5 dressing groups.

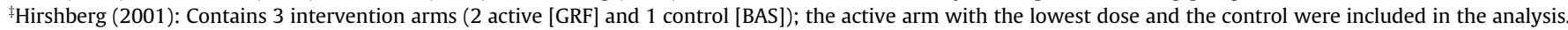
${ }^{\S}$ Hollisaz (2004): Contains 3 intervention arms, phenytoin cream was excluded from the analysis as it does not fit in any of the prespecified dressing categories.

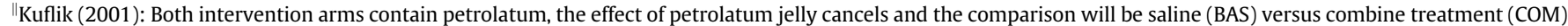

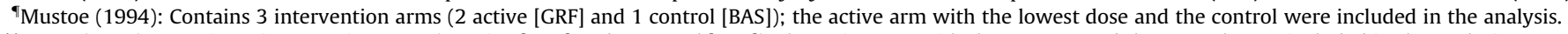

**Payne (2001): Contains 4 intervention arms ( 3 active [GRF] and 1 control [BAS]); the active arm with the GM-CSF and the control were included in the analysis.

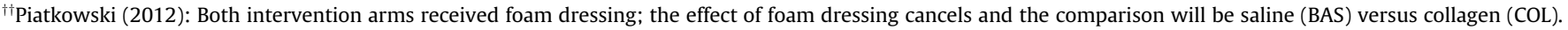

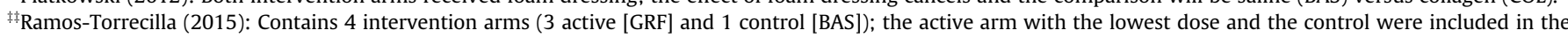
analysis.

${ }^{\S}$ Rees (1999): Contains 4 intervention arms ( 3 active [GRF] and 1 control [BAS]); the active arm with the lowest dose and the control were included in the analysis.

estimates significantly, but differed in terms of error estimation (confidence intervals) (Supplementary Material S4).

\section{Sensitivity Analysis and Assessment of Bias}

Sensitivity analysis restricting the network to studies that assessed healing between 6 and 12 weeks after treatment $(n=28)$, showed that the results remain robust to these changes in the selection criteria, revealing that foam, active wound dressing, and hydroactive wound dressing are the only treatment options (Supplementary Material S5).

The most common deficiencies in safe-guarding against bias were: participants and personnel not blind to study group allocation (6 studies) or not clearly stated (354 studies); allocation concealment not properly conducted (4 studies) or not stated (32 studies); and outcome assessors not blind to study group allocation (6 studies), or not stated (26 studies) (Supplementary Material S2). Results after 

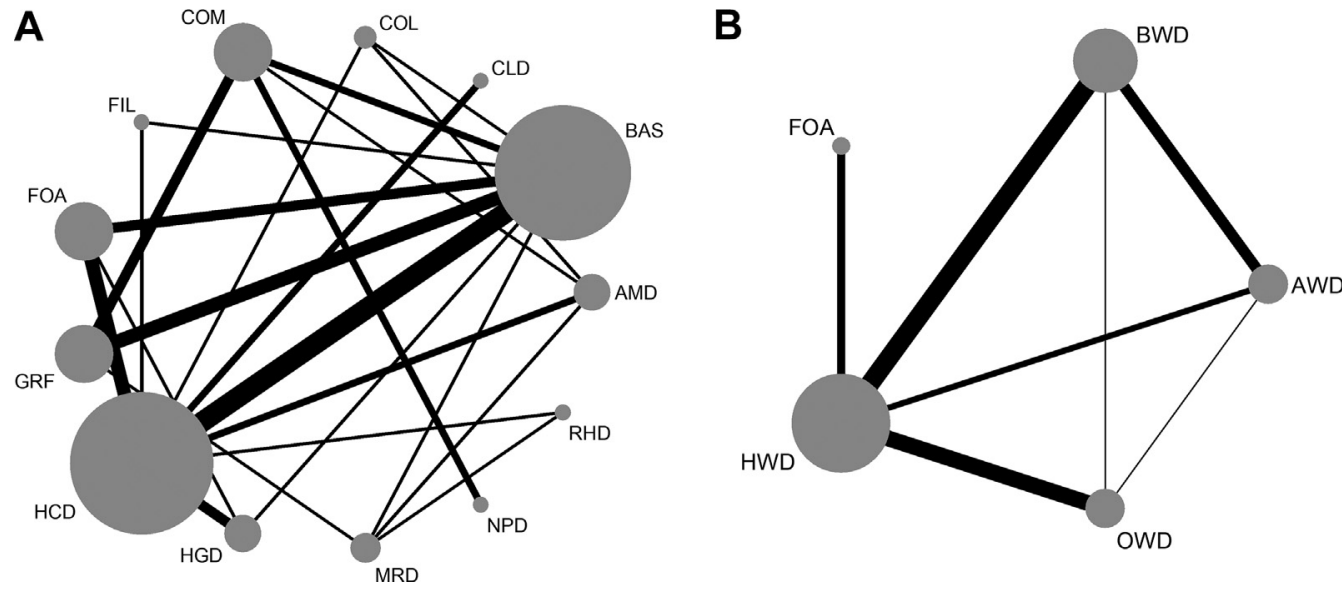

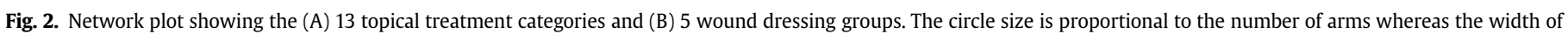

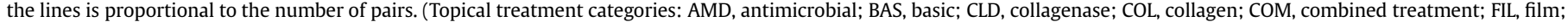

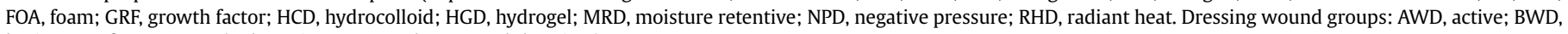
basic; FOA, foam; HWD, hydroactive; OWD, other wound dressing.)

application of the quality effects model ${ }^{35}$ were not different to the main results (Supplementary Material S6).

Comparison-adjusted funnel plots (Supplementary Material S7) demonstrated little evidence of asymmetry. There was minimal inconsistency across treatment networks, with $\bar{H}=1.20$. There was little inconsistency across direct and indirect effects $(H<3.0)$ for each of the treatment comparison pairs, including when the network was restricted in sensitivity analyses.

\section{Discussion}

The results of the network meta-analysis that included 40 RCTs involving 1757 participants, comparing 5 dressing groups revealed that foam and active dressings are the most effective treatments for healing PIs. Although the effect size of all dressing groups was higher than basic wound dressings, the uncertainty was also high, which means that these results need confirmation.

A major issue in the recent network meta-analysis may have been the approach the researchers used to group PI topical treatments, leading to a sparse network, ${ }^{23}$ and we avoided this by creating groups of tentatively similar mechanisms of action. Another key strength of the current study is the use of the GPM framework, which does not require assumptions that are not stated explicitly or cannot be verified when the method is applied. In comparison, the multivariate frequentist framework commonly used in other network meta-analyses $^{21}$ assumes that if there is no common comparator in the network, this then has to be handled by augmenting the data set using fictional arms with high variance. This requires a decision as to what constitutes a sufficiently high variance and therefore may not always be impartial. ${ }^{81}$ Additionally, the GPM framework has fewer assumption (ie, transitivity and independence of treatment effects between studies) than the multivariate frequentist framework that also requires distributional assumptions as well as augmented data sets (using fictional study arms of high variance) when studies lack the reference treatment. ${ }^{34}$

The absence of robust research in this area and the extensive heterogeneity of dressings makes it difficult for researchers to provide clear advice to clinicians and decision makers about safe and effective PI treatment options for patients. Although the findings from our analysis contribute to decision making related to choice of therapy and topical treatments, they should be considered carefully. Given the huge variety of treatment options now available within the health industry, clinicians should also consider contextual factors such as wound characteristics, patient preference, and cost. However, the results of this study do indicate that basic dressings should be abandoned in favor of the better options in terms of wound healing.

Despite the methodological strengths of our study, we acknowledge some limitations. First, the topical treatments included in the designated categories may have been developed by different manufacturers, had slightly different compositions, and had variation in duration of interventions between studies. Additionally, the assumption of exchangeability within category was an empirical judgment and should be considered a limitation of this network meta-analysis. Second, the network meta-analysis only focused on complete
A

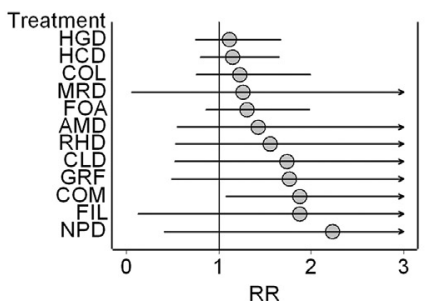

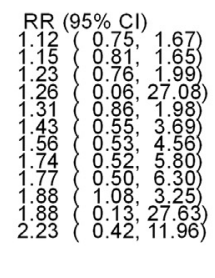

B

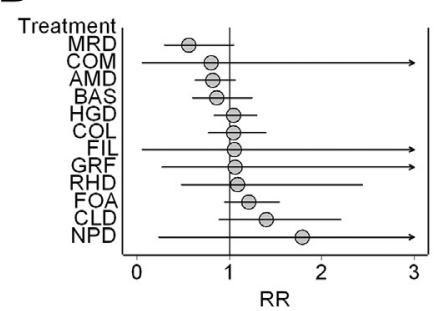

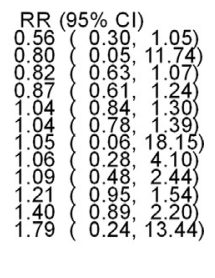

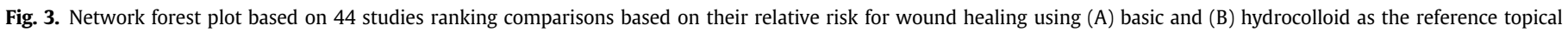

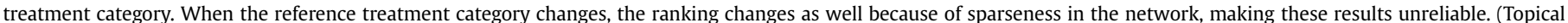

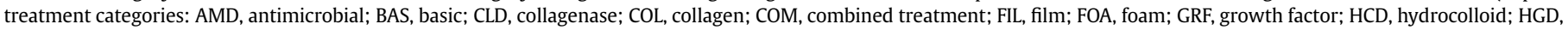
hydrogel; MRD, moisture retentive; NPD, negative pressure; RHD, radiant heat.) 
A

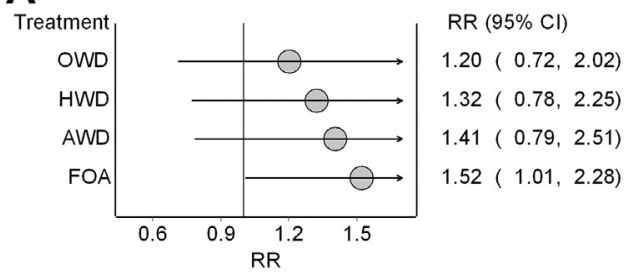

B

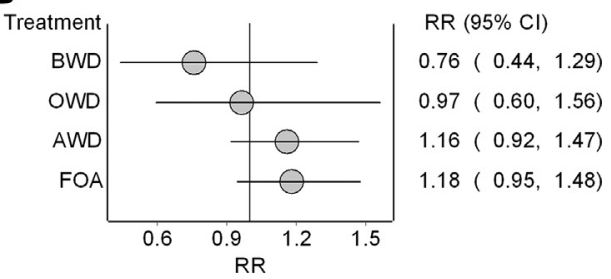

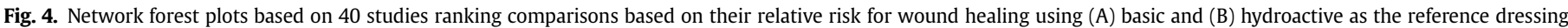

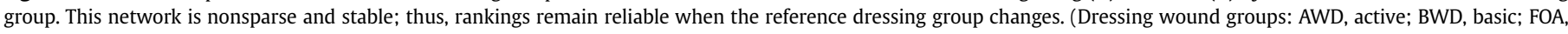
foam; HWD, hydroactive; OWD, other wound dressing.)

wound healing. Other outcomes such as time to complete healing, reduction in ulcer size, adverse events, cost, and patient quality of life should also be considered in future analyses.

\section{Conclusion}

Findings from this systematic review and network meta-analysis demonstrate evidence for the discontinuation of use of basic dressings. Hydroactive dressings are the mainstay practice, but our analysis suggests that the use of foam or active wound dressings may be more effective strategies for healing PIs. This should not be considered conclusive and more high-quality, rigorous research about the effectiveness of the dressings within these 2 groups is needed to confirm if these are indeed better than the current standard of hydroactive dressings.

\section{Acknowledgments}

The authors pay tribute to the late Jan Barendregt of Epigear International Pty Ltd, who passed away during preparation of this work, for his unwavering commitment to excellence in epidemiologic modeling and whose support has greatly enhanced this research.

The authors would like to thank Faseela Chakkalakkal Abdullakutty for her assistance during the data extraction.

\section{Supplementary Data}

Supplementary data related to this article can be found online at https://doi.org/10.1016/j.jamda.2018.10.010.

\section{References}

1. National Pressure Ulcer Advisory Panel. NPUAP announces a change in terminology from pressure ulcer to pressure injury and updates the stages of pressure injury. Available at: http://www.npuap.org/national-pressure-ulceradvisory-panel-npuap-announces-a-change-in-terminology-from-pressureulcer-to-pressure-injury-and-updates-the-stages-of-pressure-injury/; 2016. Accessed September 2, 2018.

2. National Pressure Ulcer Advisory Panel. European Pressure Ulcer Advisory Panel, Alliance PPcPI. Prevention and Treatment of Pressure Ulcers: Quick Reference Guide. Perth, Australia: Cambridge Media; 2014.

3. Edsberg LE, Black JM, Goldberg M, et al. Revised national pressure ulcer advisory panel pressure injury staging system: Revised pressure injury staging system. J Wound Ostomy Continence Nurs 2016;43:585-597.

4. Essex HN, Clark M, Sims J, et al. Health-related quality of life in hospital inpatients with pressure ulceration: Assessment using generic health-related quality of life measures. Wound Repair Regen 2009;17:797-805.

5. Coleman S, Gorecki C, Nelson EA, et al. Patient risk factors for pressure ulcer development: Systematic review. Int J Nurs Stud 2013;50:974-1003.

6. Harris AG, Leiderer R, Peer F, et al. Skeletal muscle microvascular and tissue injury after varying durations of ischemia. Am J Physiol 1996;271:H2388-H2398.

7. House S, Giles T, Whitcomb J. Benchmarking to the International Pressure Ulcer Prevalence Survey. J Wound Ostomy Continence Nurs 2011;38:254-259.

8. Vanderwee K, Clark M, Dealey C, et al. Pressure ulcer prevalence in Europe: A pilot study. J Eval Clin Pract 2007;13:227-235.
9. NHS Quality Observatory. National Safety Thermometer Data 2017. Available at: https://www.safetythermometer.nhs.uk/index.php?option=com_dashboa rd\&view=dashboard\&id=5\&Itemid=137; 2017. Accessed September 2, 2018.

10. Smith IL, Nixon J, Brown S, et al. Pressure ulcer and wounds reporting in NHS hospitals in England part 1: Audit of monitoring systems. J Tissue Viability 2016;25:3-15.

11. Coleman S, Smith IL, Nixon J, et al. Pressure ulcer and wounds reporting in NHS hospitals in England part 2: Survey of monitoring systems. J Tissue Viability 2016:25:16-25.

12. VanGilder C, Amlung S, Harrison P, et al. Results of the 2008-2009 International Pressure Ulcer Prevalence Survey and a 3-year, acute care, unit-specific analysis. Ostomy Wound Manage 2009:55:39-45.

13. Guest JF, Ayoub N, Mcllwraith T, et al. Health economic burden that wounds impose on the National Health Service in the UK. BMJ Open 2015;5:e009283.

14. Agency for Healthcare Research and Quality. Preventing pressure ulcers in hospitals. Available at: https://www.ahrq.gov/professionals/systems/hospital/ pressureulcertoolkit/index.html; 2014. Accessed September 2, 2018.

15. Nguyen KH, Chaboyer W, Whitty JA. Pressure injury in Australian public hospitals: A cost-of-illness study. Aust Health Rev 2015;39: 329-336.

16. Stansby G, Avital L, Jones K, et al. Prevention and management of pressure ulcers in primary and secondary care: Summary of NICE guidance. BMJ 2014; 348:g2592.

17. McInnes E, Jammali-Blasi A, Bell-Syer SE, et al. Support surfaces for pressure ulcer prevention. Cochrane Database Syst Rev 2015;9:CD001735.

18. Dumville JC, Keogh SJ, Liu Z, et al. Alginate dressings for treating pressure ulcers. Cochrane Database Syst Rev 2015;5:CD011277.

19. Dumville JC, Stubbs N, Keogh SJ, et al. Hydrogel dressings for treating pressure ulcers. Cochrane Database Syst Rev 2015;2:CD011226.

20. Dumville JC, Webster J, Evans D, et al. Negative pressure wound therapy for treating pressure ulcers. Cochrane Database Syst Rev 2015;5: CD011334.

21. Westby MJ, Dumville JC, Soares MO, et al. Dressings and topical agents for treating pressure ulcers. Cochrane Database Syst Rev 2017;6:CD011947.

22. Walker RM, Gillespie BM, Thalib L, et al. Foam dressings for treating pressure ulcers. Cochrane Database Syst Rev 2017;10:CD011332.

23. Norman G, Westby M, Dumville J, et al. Conducting network meta-analysis with sparse data and many interventions: Recent examples and the issues they raise. Available at: https://colloquium.cochrane.org/abstracts/conducting network-meta-analysis-sparse-data-and-many-interventions-recent-examp les-and; 2018. Accessed September 2, 2018.

24. Moher D, Liberati A, Tetzlaff J, et al. Preferred reporting items for systematic reviews and meta-analyses: The PRISMA statement. PLoS Med 2009;6: e1000097.

25. Centre for Research in Evidence Based Practice. Systematic review accelerator-Polyglot search translator. Available at: http://crebp-sra.com/\#/poly glot; 2017. Accessed September 2, 2018.

26. Zheng X, Li J. Comparison of the treatment of hydrocolloid and saline gauze for pressure ulcer: A meta-analysis of randomized controlled trials. Int J Clin Exp Med 2015;8:20869-20875.

27. Jull AB, Rodgers A, Walker N. Honey as a topical treatment for wounds. Cochrane Database Syst Rev 2008;4:CD005083.

28. Ouzzani M, Hammady H, Fedorowicz Z, et al. Rayyan-A web and mobile app for systematic reviews. Syst Rev 2016;5:210.

29. Horn T. Wound dressings-Overview and classification. Unfallchirurg 2012; 115:774-782.

30. Higgins JP, Altman DG, Gøtzsche PC, et al. The Cochrane Collaboration's tool for assessing risk of bias in randomised trials. BMJ 2011;343:d5928.

31. Doi SA, Barendregt JJ. A generalized pairwise modelling framework for network meta-analysis. Int J Evid Based Healthc 2018;16:187-194.

32. Bucher HC, Guyatt GH, Griffith LE, et al. The results of direct and indirect treatment comparisons in meta-analysis of randomized controlled trials. J Clin Epidemiol 1997;50:683-691.

33. Doi SAR, Barendregt JJ, Khan S, et al. Advances in the meta-analysis of heterogeneous clinical trials, I: The inverse heterogeneity model. Contemp Clin Trials 2015;45:130-138. 
34. White IR, Barrett JK, Jackson D, et al. Consistency and inconsistency in network meta-analysis: Model estimation using multivariate meta-regression. Res Synth Methods 2012;3:111-125.

35. Doi SA, Barendregt JJ, Khan S, et al. Advances in the meta-analysis of heterogeneous clinical trials, II: The quality effects model. Contemp Clin Trials 2015; 45:123-129.

36. Chaimani A, Salanti G. Using network meta-analysis to evaluate the existence of small-study effects in a network of interventions. Res Synth Methods 2012; 3:161-176.

37. Alm A, Hornmark AM, Fall PA, et al. Care of pressure sores: A controlled study of the use of a hydrocolloid dressing compared with wet saline gauze compresses. Acta Derm Venereol Suppl (Stockh) 1989;149:1-10.

38. Aguiló Sánchez S, Figueiras Mareque L, Quintillà Gatnau A, et al. Traditional dressings or cures in a moist environment? Rev Enferm 2001;24:50-54.

39. Ashby RL, Dumville JC, Soares MO, et al. A pilot randomised controlled trial of negative pressure wound therapy to treat grade III/IV pressure ulcers. Trials 2012;13:119.

40. Bale S, Squires D, Varnon T, et al. A comparison of two dressings in pressure sore management. J Wound Care 1997;6:463-466.

41. Banks V, Bale S, Harding K. The use of two dressings for moderately exuding pressure sores. J Wound Care 1994;3:132-134.

42. Banks V, Bale SE, Harding KG. Comparing two dressings for exuding pressure sores in community patients. J Wound Care 1994;3:175-178.

43. Belmin J, Meaume S, Rabus MT, et al. Sequential treatment with calcium alginate dressings and hydrocolloid dressings accelerates pressure ulcer healing in older subjects: A multicenter randomized trial of sequential versus nonsequential treatment with hydrocolloid dressings alone. J Am Geriatr Soc 2002;50:269-274.

44. Brod M, McHenry E, Plasse TF, et al. A randomized comparison of poly-hema and hydrocolloid dressings for treatment of pressure sores. Arch Dermatol 1990;126:969-970.

45. Brown-Etris M, Fowler E, Papen J, et al. Comparison and evaluation of the performance characteristics, usability and effectiveness on wound healing of Transorbent versus Duoderm CGF. Paper presented at: Fifth European Conference on Advances in Wound Management; 21-24 November, 1995; Harrogate, UK.

46. Brown-Etris $\mathrm{M}$, Milne $\mathrm{C}$, Orsted $\mathrm{H}$, et al A prospective, randomized, multisite clinical evaluation of a transparent absorbent acrylic dressing and a hydrocolloid dressing in the management of stage II and shallow stage III pressure ulcers. Adv Skin Wound Care 2008;21:169-174.

47. Burgos A, Gimenez J, Moreno E, et al. Cost, efficacy, efficiency and tolerability of collagenase ointment versus hydrocolloid occlusive dressing in the treatment of pressure ulcers. A comparative, randomised, multicentre study. Clin Drug Investig 2000;19:357-365.

48. Colwell JC, Foreman MD, Trotter JP. A comparison of the efficacy and costeffectiveness of two methods of managing pressure ulcers. Decubitus 1993; 6:28-36.

49. Darkovich SL, Brown-Etris M, Spencer M. Biofilm hydrogel dressing: A clinical evaluation in the treatment of pressure sores. Ostomy Wound Manage 1990; 29:47-60.

50. Ford CN, Reinhard ER, Yeh D, et al. Interim analysis of a prospective, randomized trial of vacuum-assisted closure versus the healthpoint system in the management of pressure ulcers. Ann Plast Surg 2002;49:55-61.

51. Gorse GJ, Messner RL. Improved pressure sore healing with hydrocolloid dressings. Arch Dermatol 1987;123:766-771.

52. Graumlich JF, Blough LS, McLaughlin RG, et al. Healing pressure ulcers with collagen or hydrocolloid: A randomized, controlled trial. J Am Geriatr Soc 2003; 51:147-154.

53. Hirshberg J, Coleman J, Marchant B, et al. TGF-beta3 in the treatment of pressure ulcers: A preliminary report. Adv Skin Wound Care 2001:14:91-95.

54. Hollisaz MT, Khedmat H, Yari F. A randomized clinical trial comparing hydrocolloid, phenytoin and simple dressings for the treatment of pressure ulcers. BMC Dermatol 2004;4:18.

55. Kim YC, Shin JC, Park CI, et al. Efficacy of hydrocolloid occlusive dressing technique in decubitus ulcer treatment: A comparative study. Yonsei Med J 1996;37:181-185.

56. Kraft MR, Lawson L, Pohlmann B, et al. A comparison of Epi-Lock and saline dressings in the treatment of pressure ulcers. Decubitus 1993;6:42-48.
57. Kuflik A, Stillo JV, Sanders D, et al. Petrolatum versus Resurfix ointment in the treatment of pressure ulcers. Ostomy Wound Manage 2001;47:52-56.

58. Landi F, Aloe L, Russo A, et al. Topical treatment of pressure ulcers with nerve growth factor: A randomized clinical trial. Ann Intern Med 2003;139: 635-641.

59. Matzen S, Peschardt A, Alsbjorn B. A new amorphous hydrocolloid for the treatment of pressure sores: A randomised controlled study. Scand J Plast Reconstr Surg Hand Surg 1999;33:13-15.

60. Moberg S, Hoffman L, Grennert ML, et al. A randomized trial of cadexomer iodine in decubitus ulcers. J Am Geriatr Soc 1983;31:462-465.

61. Muller E, van Leen MW, Bergemann R. Economic evaluation of collagenasecontaining ointment and hydrocolloid dressing in the treatment of pressure ulcers. Pharmacoeconomics 2001;19:1209-1216.

62. Mustoe TA, Cutler NR, Allman RM, et al. A phase II study to evaluate recombinant platelet-derived growth factor-BB in the treatment of stage 3 and 4 pressure ulcers. Arch Surg 1994;129:213-219.

63. Neill KM, Conforti C, Kedas A, et al. Pressure sore response to a new hydrocolloid dressing. Wounds 1989;1:173-185.

64. Nisi G, Brandi C, Grimaldi L, et al. Use of a protease-modulating matrix in the treatment of pressure sores. Chir Ital 2005;57:465-468.

65. Oleske DM, Smith XP, White P, et al. A randomized clinical trial of two dressing methods for the treatment of low-grade pressure ulcers. J Enterostomal Ther 1986;13:90-98.

66. Payne WG, Ochs DE, Meltzer DD, et al. Long-term outcome study of growth factor-treated pressure ulcers. Am J Surg 2001;181:81-86.

67. Payne WG, Wright TE, Ochs D, et al. An exploratory study of dermal replacement therapy in the treatment of stage III pressure ulcers. J Appl Res 2004;4: $12-23$.

68. Payne WG, Posnett J, Alvarez O, et al. A prospective, randomized clinical trial to assess the cost-effectiveness of a modern foam dressing versus a traditional saline gauze dressing in the treatment of stage II pressure ulcers. Ostomy Wound Manage 2009;55:50-55.

69. Piatkowski A, Ulrich D, Seidel D, et al. Randomised, controlled pilot to compare collagen and foam in stagnating pressure ulcers. J Wound Care 2012;21: $505-511$.

70. Price P, Bale S, Crook $\mathrm{H}$, et al. The effect of a radiant heat dressing on pressure ulcers. J Wound Care 2000;9:201-205.

71. Ramos-Torrecillas J, Garcia-Martinez O, De Luna-Bertos E, et al. Effectiveness of platelet-rich plasma and hyaluronic acid for the treatment and care of pressure ulcers. Biol Res Nurs 2015;17:152-158.

72. Rees RS, Robson MC, Smiell JM, et al. Becaplermin gel in the treatment of pressure ulcers: A phase II randomized, double-blind, placebo-controlled study. Wound Repair Regen 1999;7:141-147.

73. Scevola S, Nicoletti G, Brenta F, et al. Allogenic platelet gel in the treatment of pressure sores: A pilot study. Int Wound J 2010;7:184-190.

74. Sebern MD. Pressure ulcer management in home health care: Efficacy and cost effectiveness of moisture vapor permeable dressing. Arch Phys Med Rehabil 1986;67:726-729.

75. Seeley J, Jensen JL, Hutcherson J. A randomized clinical study comparing a hydrocellular dressing to a hydrocolloid dressing in the management of pressure ulcers. Ostomy Wound Manage 1999;45:39-44, 46-47.

76. Sipponen A, Jokinen JJ, Sipponen P, et al. Beneficial effect of resin salve in treatment of severe pressure ulcers: A prospective, randomized and controlled multicentre trial. Br J Dermatol 2008;158:1055-1062.

77. Sopata M, Luczak J, Ciupinska M. Effect of bacteriological status on pressure ulcer healing in patients with advanced cancer. J Wound Care 2002;11: 107-110.

78. Thomas DR, Goode PS, LaMaster K, et al. Acemannan hydrogel dressing versus saline dressing for pressure ulcers. A randomized, controlled trial. Adv Wound Care 1998;11:273-276.

79. Thomas DR, Diebold MR, Eggemeyer LM. A controlled, randomized, comparative study of a radiant heat bandage on the healing of stage 3-4 pressure ulcers: A pilot study. J Am Med Dir Assoc 2005;6:46-49.

80. Xakellis GC, Chrischilles EA. Hydrocolloid versus saline-gauze dressings in treating pressure ulcers: A cost-effectiveness analysis. Arch Phys Med Rehabil 1992;73:463-469.

81. van Valkenhoef G, Lu G, de Brock B, et al. Automating network meta-analysis. Res Synth Methods 2012;3:285-299. 